\title{
Knowledge and Utilization of Information Communication Technologies (ICTs) among Health Professionals at Debretabor Referral Hospital, Northwest Ethiopia
}

\author{
Sisay Ebabye Tsigie ${ }^{1 *}$ (Bsc, MPH), Gizealew Alazie Dagnaw ${ }^{2}$ (BSc, MSc) \\ ${ }^{1}$ Departmentof Information Science, University of Gondar, Ethiopia,Email:sis.ebe2007@ gmail.com \\ ${ }^{2}$ Department of Information Science, University of Gondar, Ethiopia, Email:gizeinstra@gmail.com
}

\begin{abstract}
Background: - Incorporation of Information Communication Technology (ICT) in health care system has gained a great momentum of acceptance globally. Thus, ICT adoption in the health system can significantly contribute to improve quality service and accessibility. However, most health care providers in Ethiopia just like other developing countries have underprivileged ICT utilization. The objective of this study is to investigate knowledge, and utilization of Information communication technology among health professionals at Debretabor Referral hospital.
\end{abstract}

Methods: - A cross-sectional study was conducted. Study participants selected using simple random sampling. Data collected through self-administered questionnaire. Descriptive and logistic regression techniques were deployed. SPSS20 was used to analysis.

Result: - 314 participants enrolled in the study giving an overall response rate of $94.9 \%$. The proportion of those who have good utilization habits for ICT was 39.9\% and about $87.2 \%$ were good ICT knowledge. Age with [AOR: 4.29, 95\% CI (1.781-10.329)], educational status (AOR: 7.57, 95\% CI 2.047-27.976), ICT training (AOR: 4.92, 95\% CI 2.7628.779), and ICT knowledge (AOR: 9.01, 95\% CI 4.01420.207) were found to be significantly associated with ICT utilization habits of health professionals.

Conclusions: - The result suggests that health professional's ICT utilization habit was relatively low. Age, educational status, ICT training and ICT knowledge were factors significantly associated to ICT utilization. Therefore the
Debretabor referral Hospital put up ICT training for healthcare in order to accrued from efficient and effective utilization of ICT.

Key words: ICT Knowledge, ICT Utilization, Debretabor referral hospital, health professionals,

\section{INTRODUCTION}

The World Health Organization defines Information communication technology is the use of different type of computers and telecommunication facilities for gathering, storing, and disseminating information globally. e-health as the cost effective use of ICT (Information and Communications Technologies) in the support of health and health related fields including healthcare services, health surveillance, education, and research[1].

The health sector has been much less effective than many other sectors in reaping reward from the applications of ICT. Software (Application): Over the years FMOH have developed various national e-health application that includes; e-HMIS, EMR, HRIS (manage/license), IFMIS, M-health, etc. Other initiatives include LIS, hub Store IS, drug dispending, etc. Has also developed and deployed to all levels. [2].

The use of (ICTs) for healthcare delivery in the developed countries has been widely explored with most developed countries making great advances[3]. Developing countries on the other hand are seeing a proliferation of e-Health pilots but few full-scale implementations[4]. Some reasons given for the case of "pilot it is" in the e-Health arena in developing countries are 
lack of infrastructure, donor funded projects and inadequate skilled personnel to manage these e-Health projects[5].

Information and Communication Technologies (ICTs) have the potential to make a major contribution to improving access and quality of health services[6]. These in turn eventually involve massive social and economic changes, as many health challenges go well beyond the health sector[7]. Information Communication and Technology (ICT) knowledge enables health care providers to enhance patient care delivery, as well as the practice and safety of care[8].

Health Science is dynamic in nature it has a change from time to time and it needs to be updated regarding knowledge. Health workers must constantly update themselves about new developments (in the area of treatment, on nature of various diseases) with the help of computers and the Internet[9].

The general objective of the study is to investigate knowledge, attitude and utilization of Information communication technology (ICT) among health professionals in Gondar University Comprehensive Specialized Hospital. And the specific objectives are: To describe knowledge of ICT among health professionals; To identify attitude of health professional on ICT, and To determine the associated factors ICT utilization among health professionals.

A Cross-Sectional Study conducted in Ethiopia on 554 health professionals working in 7 hospitals, 19 primary health centers, and 10 private clinics in the Harari region of Ethiopia in 2015. Out of those participants, $482(87.0 \%)$ of them responded to the questionnaire. Among them, 90 (18.7\%) demonstrated good knowledge of computers Age, field of study, level of education, and previous computer training participation found to be significantly associated with computer knowledge of health professionals [10].

The study conducted in Ludhiana, Punjab, India in which all the nurses $(100 \%)$ had positive attitude towards computers in health care setting hospital [11].

Insufficient time was belief to be a primary barrier to utilization of ICT by the respondents in this study. However did not view lack of interest as a primary barrier to use of ICT[12].
Other, a case study conducted in Nigerian a University teaching Hospital in 2004. From a total of 148 participants only 59 respondents (39.9\%) demonstrated good computer and internet utilization habits, while in 50 respondents $(33.8 \%)$ utilization habits were average andc in 39 (26.4\%) they were poor[13].

The study on Utilization of Information Communication Technology (ICT) among health care providers in Kenya indicated that $88.8 \%$ of the participants did not own computers while few (11.2\%) of the respondents have own computers. Only $27.6 \%$ of the respondents used computers while at work while the rest did not. Sixty one percent (61.3\%) reported computers are used for patient record management, $43.5 \%$ said they are reported for sending emails, $40.3 \%$ said browsing and data storage while $35.5 \%$ said they use it for education continuation[14].

\section{MATERIALS AND METHODS}

An institutional based cross-sectional study was, deployed to assess health professional's ICT utilization and associated factors with utilization of ICTs at Debretabor Referral Hospital. Debretabor Referral Hospital is found in Amhara national regional state, South Gondar Zone, Debretabor town. Total samples of 313 subjects were selected from the participant in the study using Stratified random sampling technique since the population is not homogeneous. Proportional allocation for each subgroup was done. Data collection was done using semistructured, self-administered questionnaire and conducted for 25 days from February 15 to March 10, 2020. The questionnaire contains four parts. Socio-demography, knowledge and utilization habit of the health professionals. The questionnaire was prepared to fill in English. Pre-test was done on 5\% (16) health professionals at Debark district hospital before two week the actual data collected. Two supervisors and six facilitators were participated in the data collection process. The study was approved by the Institutional Review Board of the University of Gondar, Faculty of Informatics. Oral informed consent wasobtained from each participant. Before distributing the questionnaire, informed to hospital's administrator about the study by showing the ethical clearance approval letter from Institutional Review Board of the University of Gondar that 
briefly stated the purpose of the study and its significance. The cleaned and edited data was entered in to EPI INFO version 7 and export to SPSS version 20 for further analysis. Frequency tables, proportions and crosstabs was used for the- descriptive analysis. Logistic regression was performed to assess the association between binary outcomes (ICT Utilization) and different explanatory variables. Bivariate analysis was first conducted for each potentially explanatory variable. Variables that satisfied that satisfied $\mathrm{p}$-value $<0.05 \mathrm{p}$-value $<0.05$ was selected for further analysis using multiple logistic regression models. The strength of association was interpreted using odds ratio (OR) and 95\% confidence interval $(\mathrm{CI}) \mathrm{P}$-value $<0.05$ was considered statistically significant in this study.

\section{ETHICAL CONSIDERATION}

Concerning to data collection, appropriate ethical clearance was taken from ethical clearance committee of the faculty of Informatics, University of Gondar and a formal letter was obtained .Further, concerned administrative bodies of Debretabor referral hospital under the study were informed about the study during data collection. Oral informed consent was obtained from each participant about the purpose, scope and expected outcome of the research. Before distributing the questionnaire, informed to hospital's administrator about the study by showing the ethical clearance approval letter from Institutional Review Board of the University of Gondar that briefly stated the purpose of the study and its significance. Anyone who was not willing to participate excluded from the study. In order to establish anonymous linkage and to maintain confidentiality and privacy the names of the respondents and Identification number were not registered on the questionnaires.

\section{RESULTS}

\subsection{Socio demographic characteristics health professionals}

A total of 314 participants were enrolled in the study giving an overall response rate of $94.9 \%$. The mean age of the study participants was $28.6( \pm 4.4)$ years. Male constitute only 159 (53.4\%) of the respondents. The majority $180(60.0 \%)$ were Nurses. Almost half of the respondents 159 (53.4\%) were single, 256 (85.9\%) were Orthodox Christians and 238(79.9\%) were BSc holders.

Table 1: Socio demographic characteristics of health professionals at Debretabor Referral hospital, $2020(n=298)$

\begin{tabular}{|c|c|c|}
\hline Variables & Category & Frequency $(\%)$ \\
\hline \multirow[t]{3}{*}{ Age } & $20-25$ & $43(14.4 \%)$ \\
\hline & $25-30$ & $153(51.3 \%)$ \\
\hline & $\geq 30$ & $102(34.2 \%)$ \\
\hline \multirow[t]{2}{*}{ Sex } & Male & $159(53.4 \%)$ \\
\hline & Female & $139(46.6 \%)$ \\
\hline \multirow{3}{*}{$\begin{array}{l}\text { Marital } \\
\text { Statues }\end{array}$} & Single & $159(53.4 \%)$ \\
\hline & Married & $131(44 \%)$ \\
\hline & Divorced & $8(2.7 \%)$ \\
\hline \multirow[t]{4}{*}{ Religion } & Orthodox & $256(85.9 \%)$ \\
\hline & Muslim & $27(9.1 \%)$ \\
\hline & Protestant & $12(4 \%)$ \\
\hline & Catholic & $3(1 \%)$ \\
\hline \multirow[t]{6}{*}{ Profession } & Doctor & $12(4 \%)$ \\
\hline & Nurse & $180(60 \%)$ \\
\hline & Laboratory & $26(8.7 \%)$ \\
\hline & Pharmacy & $19(6.4 \%)$ \\
\hline & Midwifery & $25(8.4 \%)$ \\
\hline & Other $* *$ & $36(12.1 \%)$ \\
\hline \multirow{4}{*}{$\begin{array}{l}\text { Educational } \\
\text { Status }\end{array}$} & $\mathrm{MSc}$ & $34(11.4 \%)$ \\
\hline & $\mathrm{BSc}$ & $238(79.9 \%)$ \\
\hline & Diploma and & $26(8.7 \%)$ \\
\hline & Below & \\
\hline \multirow{4}{*}{$\begin{array}{l}\text { Service In } \\
\text { Year }\end{array}$} & $\leq 5$ years & $175(58.7 \%)$ \\
\hline & $5-10$ years & $96(32.2 \%)$ \\
\hline & $10-15$ years & $12(4 \%)$ \\
\hline & $\geq 15$ years & $14(4.7 \%)$ \\
\hline
\end{tabular}


Sisay Ebabye Tsigie et al., International Journal of Advanced Trends in Computer Science and Engineering, 10(2), March - April 2021, 1324 - 1330

\subsection{Health professional's knowledge on ICT}

It was shown from the study that $240(80.5 \%)$ of the respondents had good ICT knowledge. Of which 132 (51\%) were female. $85(85.6 \%)$ of the respondents correctly answered which is a global communication network is internet. 237(79.5\%) responded that printer is an output device. 222(74.5\%) knew a computer network is an interconnected of computers located in different places. Most of knowledge measuring question is answered correctly by respondents one question is answer below fifty percent is ' $124(41.6 \%)$ only know medical websites for professional updates 'from those 53(42.7\%) Pub Med, 46(37.4\%) MEDLINE and most of them including those 116 (94\%) MED up-to-date.

Table 2: knowledge of ICT among health professionals at Debretabor Referral hospital, 2020 (n = 298)

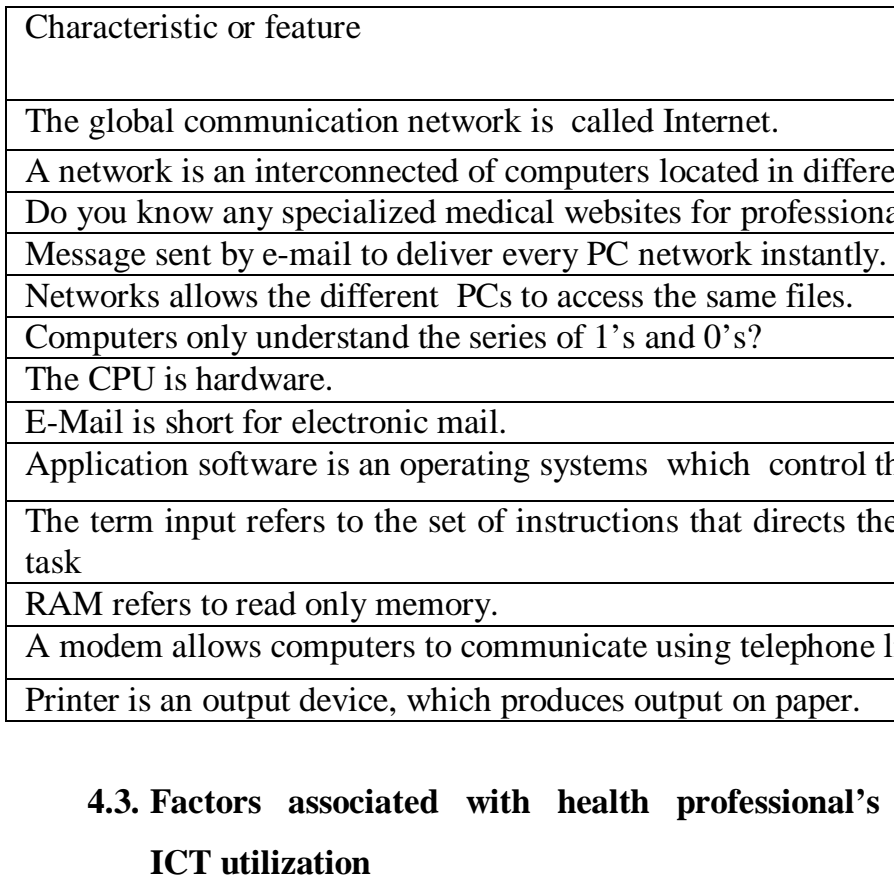

The result of the study indicated that from the total of respondents 119 (39.9\%) had good ICT utilization habit.

As indicated below in the table 3 after bivariate logistic regression analysis of each independent variable to dependent variable with p- values less or equal to 0.2 , was fitted to multiple logistic regression for further analysis between independent and dependent variables and $\mathrm{p}$-value less than 0.05 was taken as significant. In multiple logistic regression those independent variables; Age, Educational Status, ICT Training and ICT Knowledge had statistically significant association with ICT Utilization. Health professionals who had younger age group (20-25 years) were approximately 4.29 times more likely to utilize ICT as compared to health professionals age group 30 years and

\begin{tabular}{|l|l|l|}
\multirow{2}{*}{} & \multicolumn{2}{|l|}{ Knowledgeable to IC } \\
\cline { 2 - 3 } & $\mathbf{N}$ & $\mathbf{\%}$ \\
\hline & 255 & 85.6 \\
\hline & 222 & 74.5 \\
\hline & 124 & 41.6 \\
\hline & 166 & 55.7 \\
\hline he updates? & 180 & 60.4 \\
\hline & 149 & 50.0 \\
\hline & 157 & 52.7 \\
\hline & 203 & 68.1 \\
\hline & 194 & 65.1 \\
\hline & 183 & 61.4 \\
\hline & & \\
\hline & 181 & 60.7 \\
\hline & 166 & 55.7 \\
\hline
\end{tabular}

older [AOR:4.289. 95\% CI (4.289-5.37)]. Additionally health professionals those with masters were 7.568 times more likely to utilize ICT than those with diploma and below health professionals [AOR: 7.568, 95\% CI;(2.04727.976)].Health professionals Who had good knowledge 9.06 times more likely to utilize ICT than who had poor knowledge [AOR: 9.06, 95\% CI;(4.014-20.207)] health professionals those health professionals who had previous ICT training were 4.924 times more likely to utilize ICT than those who did not have any kind of ICT training [AOR:4.924,95\%CI;(2.762-8.776)] . 
Sisay Ebabye Tsigie et al., International Journal of Advanced Trends in Computer Science and Engineering, 10(2), March - April 2021, 1324 - 1330

Table 3: Bivariate and multivariate logistic regression analysis ICT Utilization at Debretabor Referral hospital, $2020(\mathrm{n}=298)$

\begin{tabular}{|c|c|c|c|c|c|}
\hline \multirow{2}{*}{\multicolumn{2}{|c|}{ Predictors variable }} & \multicolumn{2}{|c|}{ Utilization } & \multirow{3}{*}{$\frac{\operatorname{COR}(95 \% \mathrm{CI})}{2.546(1.228-5.280)^{*}}$} & \multirow{3}{*}{$\frac{\operatorname{AOR}(95 \% \text { CI })}{4.289(1.781-10.329)}$} \\
\hline & & \multirow{2}{*}{$\begin{array}{l}\text { Good } \\
25\end{array}$} & \multirow{2}{*}{$\begin{array}{l}\text { Poor } \\
18\end{array}$} & & \\
\hline Age & $20-25$ & & & & \\
\hline & $25-30$ & 58 & 95 & $1.119(0.665-1.855)$ & $1.341(0.717-2.506)$ \\
\hline & $\geq 30$ & 36 & 66 & 1.00 & 1.00 \\
\hline \multirow[t]{2}{*}{ Sex } & Male & 61 & 98 & 1.00 & 1.00 \\
\hline & Female & 58 & 81 & $(0.546-1.385)$ & $0.731(0.430-1.244)$ \\
\hline \multirow[t]{2}{*}{ Marital status: } & never married & 65 & 94 & $(0.266-4.992)$ & $1.424(0.258-7.861)$ \\
\hline & Ever Married & 54 & 85 & 1.00 & 1.00 \\
\hline \multirow[t]{6}{*}{ Profession } & Doctor & 11 & 1 & $2.800(0.711-11.030)$ & $1.796(0.390-8.278)$ \\
\hline & Nurse & 63 & 117 & $0.754(0.363-1.564)$ & $0.660(0.278-1.566)$ \\
\hline & Laboratory & 15 & 21 & $1.200(0.434-3.854)$ & $1.079(0.137-8.524)$ \\
\hline & Pharmacy & 12 & 14 & $1.260(0.412-3.854)$ & $0.582(0.60-5.664)$ \\
\hline & Midwife & 9 & 10 & $1.292(0.463-3.609)$ & $1.411(0.451-4.417)$ \\
\hline & Other** & 20 & 17 & 1.00 & 1.00 \\
\hline \multirow[t]{2}{*}{ Work position } & $\begin{array}{l}\text { Health } \\
\text { provider }\end{array}$ & 101 & 164 & $7.000(1.386-35.345)$ & $1.851(0.484-7.078)$ \\
\hline & Department head & 18 & 15 & 1.00 & 1.00 \\
\hline \multirow[t]{3}{*}{ Education status } & $\mathrm{MSc}$ & 25 & 9 & $7.540(2.378-23.904)^{*}$ & $7.568(2.047-27.976)^{*}$ \\
\hline & $\mathrm{BSc}$ & 87 & 11 & $1.564(0.632-3.869)$ & $1.552(0.563-4.278)$ \\
\hline & $\begin{array}{l}\text { Diploma } \quad \& \\
\text { below }\end{array}$ & 7 & 19 & 1.00 & 1.00 \\
\hline \multirow[t]{6}{*}{ Department } & Inpatient & 2 & 6 & 1.00 & 1.00 \\
\hline & Out patient & 30 & 56 & $1.667(0.312-8.892)$ & $1.268(0.166-9.715)$ \\
\hline & Emergency & 56 & 84 & $1.339(0.245-7.322)$ & $1.059(0.141-7.980)$ \\
\hline & Pharmacy & 9 & 10 & $2.500(0.397-15.749)$ & $2.268(0.254-20.236)$ \\
\hline & Laboratory & 11 & 12 & $2.250(0.346-14.611)$ & $1.713(0.92-31.830)$ \\
\hline & Other & 11 & 11 & $2.292(0,367-14.323)$ & $1.956(0.116-32.855)$ \\
\hline \multirow[t]{2}{*}{ ICT training } & Yes & 49 & 136 & $4.518(2.378-7.456)^{*}$ & $4.924(2.762-8.779)^{*}$ \\
\hline & No & 70 & 43 & 1.00 & 1.00 \\
\hline \multirow[t]{2}{*}{ Knowledge } & Poor & 44 & 14 & 1.00 & 1.00 \\
\hline & Good & 75 & 165 & $6.914(3.572-13.384)^{*}$ & $9.006(4.014-20.207)^{*}$ \\
\hline
\end{tabular}

* P-value $<0.05$ significantly associated

** Other $=$ Those Health professional included -

Environmental, Physiotherapy, Radiographer, Anesthesia,

Ophthalmologists, Psychiatry, and Health officer.

\section{DISCUSSION}

Out of 314 respondents in this study ICT, utilization habit of health professionals was $39.9 \%$ with $95 \%$ CI; $(34.2 \%$, 45.6\%). The result was higher than study conducted in Addis Ababa Ethiopia (19.3\%) (8). and Harare Ethiopia (29.5\%) (13). this variation might be due to the difference in study years and area. Since study participants in my study includes higher education level health professional staff compared with Harare study. It might be also attributed to a difference in study participants between the studies; previous studies included health professionals working at the health centers, which have less computer access and information communication technology infrastructure. The current study result was similar with study conducted in Nigeria $(39.8 \%)$ (20).However the result of this study was lower than the study conducted in Austria $75 \%$ (18), Texas 81\% (19), United States 91\% (16).and Belgium (93\%) at general acute 
care hospital and $94 \%$ at psychiatric hospital working health professional is good ICT utilization habit (17).These differences might be attributed to the infrastructure and economical status of the countries. The proportion of knowledge among health professionals towards ICT was $80.5 \%$ with $95 \%$ CI; $(75.8 \%, 84.9 \%)$. In this study participants with good knowledge had 9 times utilize ICT as The results of this study have important implications for the knowledgeand utilization status of health professionals in the health facilities. The study indicated that majority of the health professionals had low level of ICT utilization and most of them are high level of ICT knowledge.

The study revealed high number of health professions was knowledgeable to ICT however low utilization of ICT among the health care professionals. The younger age groups and increment educational level by itself had more likely to have better utilization of ICT applications compared to older ages and low educational level of health professionals. Trained in ICT were mostly trained before joining the health service a fact that show training receive relevant to ICT utilization. ICT training among the health care providers relatively low proportion of the respondents recognized the benefits accrued

\section{REFERENCES}

[1] W. -, "Telemedicine Opportunities and Developments in Member States," Report on the second global survey on eHealth Global Observatory for eHealth series, vol. .;2:96., 2010.

[2] T. J. Alexander D, Anne K, Jorg A, Karl AS, Veli NS. Report on Methodology for evaluating the socioeconomic impact of interoperable HER and ePrescribing systems. , "Study on the economic impact of interoperable electronic health records and e-Prescription in Europe.," Report on Methodology for evaluating the socioeconomic impact of interoperable HER and e-Prescribing systems., 2008. compared with their counter parts with $[\mathrm{AOR}]=9.01 ; 95 \% \mathrm{CI}$ (4.014-20.207)*. This might be due to understand benefit of ICT to professionals daily activates. Finding of this study was inconsistent with studies in India that showed that level of education was not significantly associated with ICT utilization (15).

from ICT utilization in the health care system. Despite the infrastructure development in the health facilities, lack of ICT facilities majored as the main reason that hampered ICT utilization among the healthcare providers. The study further revealed there is limited available ICT facilities which may cause delay in service provision or result to low utilization rate and further damage to the available ICT facilities.

\section{ACKNOWLEDGEMENTS}

We would like to thank university of Gondar, College of Informatics for its ethical approval. Furthermore, our deepest gratitude goes to the Debretabor Referral hospital staffs, participants and data collectors. The study is funded by the authors.

[3] D. A. Howitt P, Yang G-Z, Ashrafian H, Atun R, Barlow J, 2012;, "Technologies for global health," et al. . Lancet., vol. 380(9840):507-35., 2012.

[4] S. C. Lewis T, Lagomarsino G, Schweitzer J. , "EHealth in low- and middle-income countries: findings from the Center for Health Market Innovations," Bull World Health Organ, vol. 90(5):332-40, 2012.

[5] S. J. Yusif S, " Preparedness for eHealth in developing countries," the case of Ghana. J Health Inform Dev Ctries., vol.;8(2). 2014.

[6] J. E. G. Brian E. Perron HOT, Jon Margerum-Leys . 2010;, "Information and Communication Technologies in Social Work," Advances in Social Work, vol. 11: 1, 67, 2010. 
[7] H. M. Jackie D BT, Roberto Ramirez, . , "Improving health, connecting people : the role of ICTs in the health scoter of developing countries A frame work paper.," wwwwho int/mdg/publications/mdg report/en/indexhmi., 2/24/2017 2006 .

[8] C. e. indicators/, "Health and Health Related Indicators," 3/4/2017 2006.

[9] C. e. indicators/, "Health and Health Related Indicators ; ," evadible at http:// cnhde. ei, Accessed on February 23, 20172006.

[10] T. A. Kalid Alwan, ; Binyam Tilahun : , "Knowledge and Utilization of Computers Among Health Professionals in a Developing Country," JMIR Human Factors, vol. vol. 2 | 3/5/2017 2015 .

[11] A. P. f. I. A. S. R. f. a. T.-R. World?:, "What PISA Studies Tell Us (Programme for International Student Assessment. OECD; ," 2006.

\section{ABBREVIATIONS}

AOR=Adjusted Odd Ratio; CMHS: College of medicine and health sciences;

$\mathrm{CI}=$ Confidence Interval;

ICT = Information communication technology;

IT=Information technology;
[12] J. H. O. Cholo . W Odiwuor, Fransisca M ,Joseph M, Chepkutto Y, Lynnete M , Jackline N ,Beatrice $\mathrm{K}$, Catherine $\mathrm{N}$; , , "Utilization of Information Communication Technology (ICT) Among Health Care Providers in Gatundu North District of Kiambu County," vol. 1025-1029, 3/4/2017 Kenya 2015

C. Alison Annet K. : : 74th IFLA General Conference and Council, "Globalization challenges of medical education library services in Uganda," World Library and Information Congress Available at http://www.ifla.org/IV/ifla74/index.htm, , 2008.

[14] Rowena J. Cullen "Evidence-Based Practice: Knowledge, Attitudes And Beliefs Of Physiotherapists In Nigeria," 3/4/2017 2004,.

e-Health=Electronic health;

$\mathrm{FMOH}=$ Federal Ministry of Health;

SPSS=Statistical Package for Social Sciences

$\mathrm{COR}=$ Crude odd ratio

EMR=Electronic Medical Record

FMOH=Federal Ministry of Health

HIS=Hospital Information System

$\mathrm{IS}=$ Information System

$\mathrm{WHO}=$ World Health Organization 